\title{
Angiogenesis Inhibitor Derived from Angiostatin Active Sites
}

\author{
Kyoungsoo Park, Dongyeol Lim, ${ }^{\dagger}$ Sang-Don Park, ${ }^{\dagger}$ Min-Young Kim, ${ }^{;}$and Yangmee Kim ${ }^{*}$ \\ Department of Chemistry and Bio/Molecular Informatics Center, Konkuk Lniversity, Seoul 143-701, Korea \\ ${ }^{\dagger}$ Department of Applied Chemistry, Sejong University; Seoul 143-747, Korea \\ ${ }^{\ddagger}$ AngioLab, Inc., Daejeon 302-735. Korea \\ Received April 1, 2004
}

\begin{abstract}
Angiogenesis is essential for the growth and persistence of solid tumors. Their metastases, anti-angiogenesis could lead to the suppression of tumor growth. One of the main strategies of cancer treatment is developing molecules of anti-angiogenic activity. In this study, two angiogenic inhibitors, Ang3 (KI.FIP) and Ang4 (XI.FI)F) derived from KI.YISY, which is the secpuence of angiostatin active sites kringle 5 , were designed and synthesized. Previously we reported the activities and structures of two inhibitors, Angl (KI.YDY) and Ang2 (KI.WIP). In order to investigate the effect of Phe substitution, Ang 3 was designed with a seguence of KL.FDF. In order to reduce conformational flexibility of side chain in Lys, Ang4 was designed with a sequence of XI.FDF, where $X$ has amino substituted phenyl ring. Solution structures of those inhibitors were investigated using NMR spectroscopy and their activities as angiogenesis inhibitors were studied. Angl and Ang2 show angiogenic activities, while Ang3 and Ang4 have no activities and have extended structures compared to Angl and Ang2. Therefore, Phe rings do not have effective hydrophobic interactions with other aromatic residues in Ang 3 and Ang4. The representative structure of Ang2 has a stable intramolecular hydrogen bond. Therefore, intramolecular hydrogen bonding might be more important in stabilizing the structure than the hydrophobic interactions in these inhibitors. More rigid structure, which can be expected to have higher activities and better match with the receptor bound conformations, can be obtained with a constrained cyclic structure. Further peptidonimetic approaches should be tried to develop angiogenesis inhibitors.
\end{abstract}

Key Words : Angiogenesis inhibitor, Kringle, CAM assay, Peptidomimetics, Structure

\section{Introduction}

The formation of new blood vessels is crucial for tissue regeneration and for efficient tumor growth, and requires the concerted action of various angiogenic factors and inhibitors. Angiogenesis is a complex process of new blood vessel formation, which is essential for cell reproduction, development and wound repair under normal condition. This process involves endothelial cell proliferation. migration, and membrane degradation. Since angiogenesis is important for the growth and metastasis of tumors, many studies are being focused on the understanding of angiogenesis and inhibitors have received particular attention because of their therapeutic potential. ${ }^{1.2}$ Now one of the main strategies of cancer treatment is developing molecules with anti-angiogenic activity. ${ }^{3-6}$

Angiostatin, a proteolytic fragment of human plasminogen, is known to have profound inhibitory activity of angiogenesis by blocking the proliferation and migration of endothelial cell. ${ }^{78}$ This protein consists of homologous four kringle domains (kringle 1-kringle 4); each containing about 80 amino acids with conserved three disulfide linkages. Kringle 5 domain of plasminogen, which shares high sequence homology with other four kringles of angiostatin, was shown

"Corresponding Auther. Fax: 82-2-447-5987: e-mail: ymkim't konkuk.alc.kr to antagonize endothelial cell growth and known to have better anti-proliferative activity than angiostatin." ${ }^{\text {"10 }}$ It has been reported that KISYDY peptide in kringle 5 may play an important role on the activity of kringle $5 . "$ We have reported the activities and the structures of two angiogenic inhibitors, Ang 1 (Kl.YDY) and Ang2 (KLWDF). ${ }^{12}$ NMRderived structures in the drug design process using peptides can belp to design new pharmaceutical agents. In this study, two angiogenic inhibitors derived from angiostatin active sites, kringle 5. Ang 3 and Ang4 were designed as listed in Table 1 and synthesized. We have investigated their solution structures using NMR spectroscopy and their activities as angiogenesis inhibitors, and tried to understand the relationships between the structures and their activities.

Table 1. Amino acid sequences of Ang1. Ang2. Ang3. and Ang4

\begin{tabular}{cl}
\hline Peptide & Sequence \\
\hline Ang1 & KLYDY-NH \\
\hline Ang2 & KLWIDH-NH \\
\hline Ang? & $\mathrm{KI}$ HIDF- $-\mathrm{NH}_{2}$ \\
\hline Ang4 & $\mathrm{XLFDF-}-\mathrm{NH}_{2}$ \\
& $\mathrm{X} \rightarrow$
\end{tabular}




\section{Materials and Method}

Peptide Synthesis. Peptide syntheses were performed on a manual synthesizer equipped with Glas-Col WS180 shaker. Peptide sequence elongation was accomplished using stepwise solid-phase synthesis as reported previously, ${ }^{12}$ Crude peptides were precipitated with cold ether and washed thoroughly with ether, then separated with prep-RP-HPI.C. and lyophilized Separation was performed using a linear gradient of water $(0.1 \%(\mathrm{v} / \mathrm{v})$ TFA) and MeCN $(0.1 \%(\mathrm{v} / \mathrm{v})$ TFA) at a flow rate $3 \mathrm{ml} / / \mathrm{min}$. Mass spectra were obtained on a double focusing mass spectrometer (JГOOL., JMSAX505WA) using FAB ionization.

Chorioallantoic Membrane (CAM) Assay. The fertilized chicken eggs were kept in a humidified incubator at $37^{\circ} \mathrm{C}$. After 3 days incubation, about $2 \mathrm{ml}$ of albumin was aspirated from the eggs, and the shell covering the air sac was punched out and removed by forceps. $25 \mu \mathrm{g}$ of Ang 3 , and Ang4 were applied to sterile Thermanox discs separately and allowed to dry under laminar flow conditions. The loaded discs were inverted and applied to the CAM surface of 5-day-old embryos through the windows. PBS (Phosphate buffered saline) was used as a control. The air sac ends of the embryo with shell were sealed with tape. Two days later, an appropriate volume of a $10 \%$ fat emulsion was injected into the 7-day embryo chorioallantois. The CAM was examined under a microscope and photographed. The anti-angiogenic effect was expressed as the percentage of the number of eggs, which showed an avascular zone of the CAM under the disc. ${ }^{13,14}$ At least twenty eggs were used for each dose of agent.

NMR Experiments and Structure Calculation. $1 \mathrm{mg}$ of peptide was dissolved in $0.45 \mathrm{ml}$, of DMSO-d $_{6}$ solvent for NMR experiment. All of the phase sensitive twodimensional experiments, such as DQF-COSY, TOCSY, NOTSY, and ROESY experiments were performed using TPPI method, i.e., time-proportional phase incrementation. ${ }^{15-19}$ TOCSY experiments were performed using $20 \mathrm{msec}$ and 50 msec MLEV-17 spin-lock mixing pulses. Mixing times of 250 and 400 msec were used for ROESY and NOESY experiments. The ${ }^{3} \mathrm{~J}_{\text {Wix }}$ coupling constants were measured from the DQF-COSY spectrum. In order to study the intramolecular hydrogen bonding. temperature coefficients were calculated using chemical shifts measured from $298 \mathrm{~K}$ to $328 \mathrm{~K}$ at every $5^{\circ}$. Spectra were recorded on a Bruker Avance-400 spectrometer at Konkuk University and at 500 $\mathrm{MHz}$. Varian instrument at KBSl. All NMR spectra were processed off-line using the FELI IX software package on the SGI workstation in our laboratory (Molecular Simulations lnc., San Diego, CA, USA).

NOFSY spectra with mixing times of $250 \mathrm{msec}$ were used to get distance constraints. The volumes of the NOFs between the two beta protons of the Tyr or Phe residues were used as references. All of the NOF intensities are divided into three classes (strong. medium, and weak) with the distance ranges of 1.8-2.7, 1.8-3.3, and 1.8-5.0 $\AA$, respectively. ${ }^{20.21}$ Nonnatural amino acid $X$ in Ang 4 was built using the lnsightll and Discover program (Molecular Simulations Inc.. San Diego, CA, USA). Structure calculations were carried out using $X-P l . O R$ version 3.851 with the topology and parameter sets topallhdg and parallhdg, respectively. ${ }^{22} \mathrm{~A}$ hybrid distance geometry-dynamical simulated annealing protocol was employed to generate the structures. ${ }^{23-26}$ A total of 50 structures were generated, and the 20 structures with the lowest energies were selected for further analysis.

\section{Results and Discussion}

CAM Assay. CAM assays were used to determine the anti-angiogenic effects of Ang3 and Ang4. Fach of peptides was applied to the CAMs of 5-day-old chicken embryos and the anti-angiogenic activity was evaluated by measuring the frequency of avascular zone, which looks white 2 days after implantation of sample. Control CAM treated with PBS in Figure IA showed no disturbance of angiogenesis. For comparison. CAMs implanted with thermanox discs loaded with Ang 3 and Ang4 are shown in Figure $1 B$ and $1 C$. We have reported that Angl and Ang2 showed white avascular zones due to inhibition of new vessel formation. However, Ang3 and Ang4 did not show any disturbance of angiogenesis at all as shown in Figure $1 \mathrm{~B}$ and $1 \mathrm{C}$.

Resonance Assignments and the Temperature Coefficients. Sequence specific resonance assignments were performed using mainly the DQF-COSY, JOCSY, and ROESY data. ${ }^{27}$ Chemical shifts of Ang3 and Ang4 in DMSO at $298 \mathrm{~K}$, referenced to JMS, are listed in lable 2 .

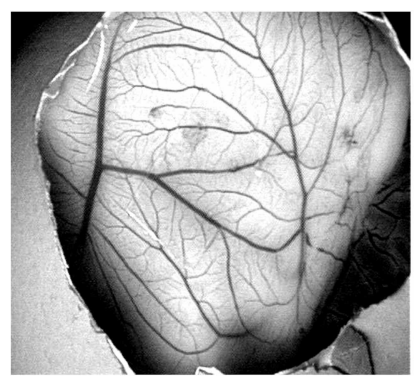

(A)

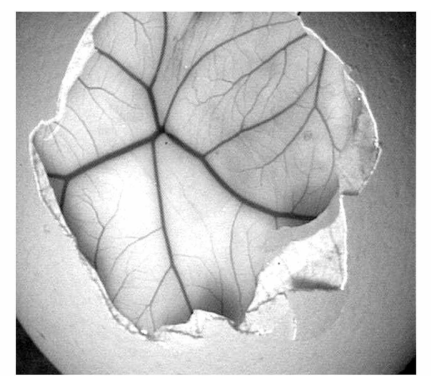

(B)

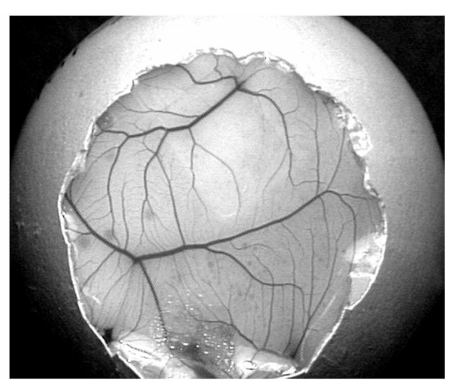

(C)

Figure 1. Anti-angiogenic activity of (B) Ang3 and (C) Ang4 in the chicken CAM (Chorioallantoic membrane) assay. (A) Control CAM Ireáled with Pl3S (Phosphale bullered saline). 
Table 2. 'H clemical shifts (ppm) for (A) Ang.3 and (B) Ang4 in DMSO at $298 \mathrm{~K}$

(A)

\begin{tabular}{|c|c|c|c|c|c|c|}
\hline \multirow{2}{*}{ Residuc } & \multicolumn{4}{|c|}{ Chemical shilt (ppm)" } & \multirow{2}{*}{$\mathrm{J}_{\mathrm{HN} \mathrm{NeH}}$} & \multirow{2}{*}{$\begin{array}{l}\text { Temperature } \\
\text { coefficient }\end{array}$} \\
\hline & $\mathrm{NH}$ & $\alpha I I$ & $\beta \mathrm{II}$ & Others & & \\
\hline$k^{-1}$ & 7.99 & 4.20 & $1.56 *$ & $\gamma 1.26 ; \delta 1.45 ; \varepsilon \div 2.74 ; \varepsilon \mathrm{NH}_{3} ; .65$ & 8 & $9.0(\mathrm{NII} 3: 7.0)$ \\
\hline $\mathrm{L}^{2}$ & 7.88 & 4.22 & $1.47^{*}$ & $\gamma 1.34 ; \delta 0.77,0.83$ & 8 & 8.5 \\
\hline $1: 3$ & 7.87 & 4.47 & 2.75 .2 .94 & $2.6117 .15: 3.5117 .31: 4117.21$ & 8 & 8.0 \\
\hline 1$)^{4}$ & 8.31 & 4.49 & 2.48 .2 .65 & & 7 & 8.5 \\
\hline$\Gamma^{5}$ & 7.83 & 4.38 & 2.85 .3 .02 & $2.6 \mathrm{H} 7.17: 3.5 \mathrm{H} 7.27: 4 \mathrm{H} 7.21$ & 8 & 10.5 \\
\hline
\end{tabular}

(B)

\begin{tabular}{|c|c|c|c|c|c|c|}
\hline \multirow{2}{*}{ Residue } & \multicolumn{4}{|c|}{ Chemical slift $(\mathrm{ppm})^{h t}$} & \multirow{2}{*}{$\mathrm{J}_{\mathrm{HN} \mathrm{NCH}}$} & \multirow{2}{*}{$\begin{array}{c}\text { Temperalure } \\
\text { cosfficient }\end{array}$} \\
\hline & N'H & $\alpha \mathrm{H}$ & $\beta \mathrm{H}$ & Others & & \\
\hline $\mathrm{X}^{\prime}$ & & & $3.51,3.57$ & $2.6117 .01: 3.5117 .23$ & & 8.5 \\
\hline 1.2 & 8.21 & 4.18 & $1.41 *$ & $\gamma 1.30 ; 80.752,0.677$ & 8 & 8.5 \\
\hline$r^{\vdots}$ & 7.96 & 4.39 & 2.66 .2 .96 & $2.6117 .11: 3.5117 .21: 4117,14$ & 8 & 9.0 \\
\hline 1$)^{4}$ & 8.20 & 4.40 & $2.25,2.42$ & & 7 & 10.0 \\
\hline$r^{5}$ & 7.79 & 4.31 & 2.77 .2 .86 & $2.6117 .09: 3.5117 .21: 41[7.14$ & 8 & 8.5 \\
\hline
\end{tabular}

"chemical shilts are relative to IMS (0 ppm)

Since these peptides are short. there are not many $\mathrm{NOF}$ connectivities exeept sequential ones. Table 2 lists the temperature coeflicients of the backbone amide protons and side chain amino protons of $[y \mathrm{~s} 1$. A reduction in temperature susceptibility (ppb/deg) has been commonly accepted as an indiealor of redued interaction with solvent. due to the intramolccular hydrogen bonding. ${ }^{28,30}$ Chenical shilt of amino protons in the side chain of [ys] in Angl and Ang2 retained in the almost same positions with the change of temperature and this resulted in temperature coelifeients smaller than $2.0 \mathrm{ppb} / \mathrm{deg} .{ }^{\text {I2 }}$ This should cortespond to a transler of electron density from the protons in the amino group in lysl as a result ol bydrogen bonding with the other atoms as electron aceepters. However. this amino proton in Ang3 has a big temperature coeflicient $(7.0 \mathrm{ppb} / \mathrm{deg})$ and these results imply that this amino proton is not involved in intramolecular hydrogen bondings. Furthermore. Ang4 does not have lys 1 because of substitution with X. Ang4 cannol form intramolecular hydrogen bonding.

Structure-Activity Relationships. It has been reported that KI.YT)Y (the region from residue 70 to residue 74 in kringle 5) is involved in lysine binding although the Lys
(A)
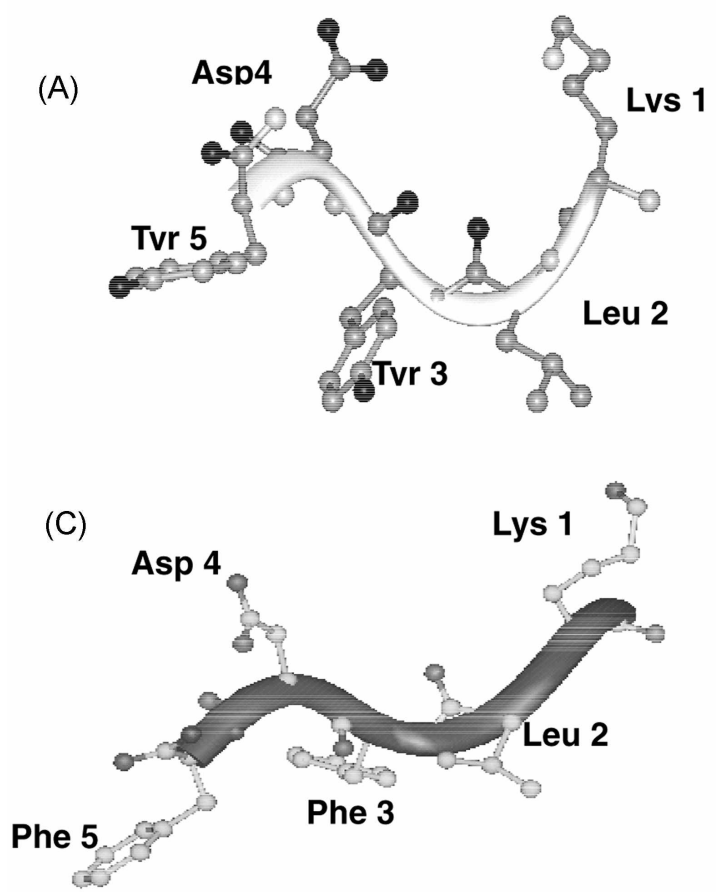

(B)

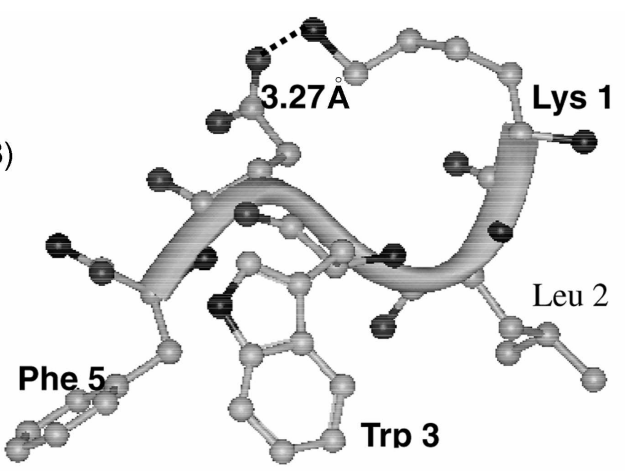

(D)

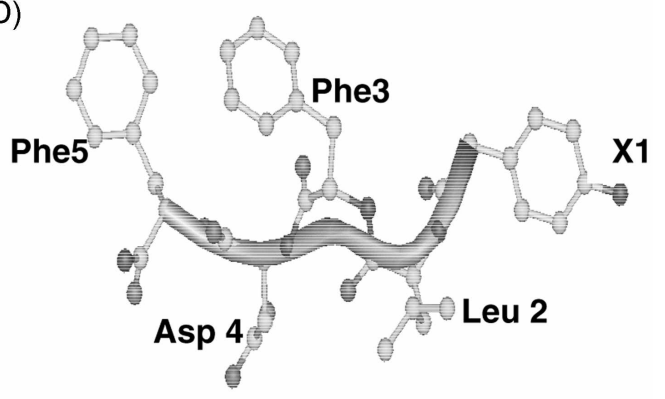

Figure 2. The lowest encrgy structures of (A) Angl, (B) Ang2, (C) Angs, and (D) Ang4 in DMSO. 
binding capability is not responsible for its bioactivity. ${ }^{11,31}$ Even though Abbott has patented KL(R)YD peptides as antiangiogenesis agents, ${ }^{31}$ there has been no report regarding conformational study of this peptide. In the crystal structure of kringle 5 , the active sequence K70-L 71-Y72-D73-Y74 has an intramolecular hydrogen bond between the side chain amino protons of Lys70 and the carboxyl oxygen of Asp73 and it results in a stable structure. KLYDY is involved in its bioactivity of kringle5. Distance between the carboxyl oxygen in Asp73 and the side chain anino nitrogen in Lys70 is $3.34 \AA$ in the crystal structure.

Peptide with five residues cannot adopt single predominant conformation in solution and they do not converge well. Figure 2 show the ribbon diagrams of the lowest energy structures of Ang3 and Ang4 with all heavy atoms, respectively. For the comparison. structures of Ang I and Ang2. which are reported previously. are shown in this figure, too. ${ }^{12}$ Even though Angl has the same amino acid sequence to that of active fragment of kringle 5, Angl has more extended solution structure than the crystal structure. Ang2 has two sets of structures while Ang 1. Ang2. and Ang3 show more diversity of structures in solution than Ang2. ${ }^{12}$ Lowest energy structure of Ang2 also has an intramolecular hydrogen bond between the side chain amino proton of Lys and the carboxyl oxygen of Aspt with the $\mathrm{N} \cdots \mathrm{O}$ distance of $3.27 \AA$ as shown in Figure 2B. Ang3 (KLFDF) has more extended structure as shown in Figure 2 and does not have angiogenic activities. This implies that $\mathrm{Phe}$ does not have effective hydrophobic interaction with other Phe. In Angt. terminal Lys was substituted by nonnatural anino acid X to increase hydrophobicity as shown in Table 1 . However. Ang4 has three aromatic rings in Ang4 have stable arrangement in one side of the peptide and this arrangement results in an extended structure.

Ang2 has more rigid solution structure than other inhibitors because of an intramolecular hydrogen bond. Indole ring in Trp3 is much bigger than the phenyl ring of Phe or Tyr and may have better face-to-edge interaction with Phenyl ring in Tyrs at the $\mathrm{C}$-terminus. enforcing more rigid and constrained conformational features of Ang2. At the other side of indole rings of Trp in Ang2. there is an intramolecular hydrogen bond between the side chain amino protons of Lysl and the carboxyl oxygen of Asp4 and it results in a stable structure. This agrees well with the result of small temperature coefficient data ${ }^{\text {l: }}$

\section{Conclusion}

Since angiogenesis is essential for the growth and persistence of solid tumors and their metastases. anti-angiogenesis could lead to the suppression of tumor growth: angiogenesis inhibitors have received attention for their therapeutic potential. In this study two angiogenic inhibitors. Ang3 (KLFDF) and Ang4 (XLFDF) were designed based on the bioactive sequence from the kringle 5 , and were compared to Angl (KLYDY) and Ang2 (KLWDF). designed previously. Ang1 and Ang2 show similar angiogenic inhibition activities. while Ang 3 and Ang4 show no angiogenic inhibition activities. Therefore. Phe rings do not have effective hydrophobic interactions with other aromatic residues in Ang3 and Ang4. The representative structure of Ang2 has a stable intramolecular hydrogen bond. According to the structure-activity relationship of these angiogenic inhibitors, it can be concluded that structural rigidity obtained from the intramolecular hydrogen bonding might be more important than the hydrophobic interaction in activities of these peptides.

Since all the peptides have diversity of structures in solution, small temperature coefficients of amino protons of Lys side chains are the strong evidence of the intramolecular hydrogen bondings in Ang2. Conformationally constrained structure with intramolecular hydrogen bondings can offer a chance to overcome the problems of flexibilities of peptides and improved the angiogenic activities. More rigid structure, which can be expected to have higher activities and better match with the receptor bound conformations. can be obtained with a constrained cyclic structure. Further peptidomimetic approaches should be tried to develop angiogenesis inhibitors.

Acknowledgements. This work was supported by a grant from Korea Research Foundation (KRF-2000-015-DP0263)

\section{References}

1. Folkmant. T. Nat. Med 1995. 1.27.

2. Folkman. J. Harvev Lect. Ser 1998,92.65.

3. Gasparini, G. Drugs 1999, 58(1), 17.

4. Gibaldi. M. J. Clin. Phamacol 1998, 38(10). 898.

5. Sim. B. K.: O'Reilly. M. S.: Liang. H.: Fortier. A. H.: He. W: Madsen. J. W: Lapeevich. R.: Nacy. C. A. Cancer Res. 1997. $57(7) .1329$.

6. Bergers, G.: Javaherian, K:; Lo, K.: Folkman, J.: Hanahan. D. Science 1999. 28t, 808 .

7. O'Reilly, M. S.: Holmgren, L.; Shing, Y.; Chen, C.; Rosenthal. R. A.: Cao. Y: Moses. M.: Lane. W. S.: Sage. E. H.: Folkman. J. Cold Spring Hart. Symp. Ouant. Biol. 1994. 59.471.

8. Cao. Y.: Chen. A.: An. S. S.: Ti. R. W.: Davidson. D.: Llinas. M. $J$ Biol. Chem. 1997, 272.22924.

9. Lu, H.; Dhanabal. M: Volk. R: Waterman. M. J.: Ramchandran, R: Knebelmann, B.: Segal. M.; Sukhatme. V. P. Biochem. Biophus. Res. Commm. 1999. 258.668.

10. Ji. W. R.: Barrientos. L. G.: Llinas. M.: Gray: H.: Villarreal. X.: DeFord. M. E.: Castellino. F. I.: Kramer. R. A.: Trail. P. A. Biochem. Biophss Res Commun. 1998. 2+7(2).414.

11. Chang, Y: Mochalkin, I; McCance, S. G.: Cheng. B.: Tulinsky, A.: Castellim, F. J. Biochemisty 1998, $37(10) .3258$

12. Park. K.: Baek. D.: Lim. D.: Park. S.: Kim. M.: Park. Y.: Kimn. Y. Bull. Korean Chem. Soc. 2001. 22. 984.

13. Suh. H. S.: Tung. E--I.: Kim. T.-H.: Lee H.-Y.: Park. Y.-H.: Kim. K.-W. Cancer-Letters 1997, 113. 117.

14. Stratin, L. M:- McMahon. G.: App. H:; Schreck, R; Kuchler. W. R; Longhi, M. P: Hui. T. H.; Tang. C; Levitzki. A.; Gazit, A.; Chent. I.: Keri. G.: Orfi. L.: Risau. W.: Flamme. I.: Ullrich. A.: Hirth. K. P.: Shawwer. L. K. Cancer Res. 1996. 56. 3540.

15. Derome. A.: Willamson. M. J. Magn. Reson. 1990. 88. 177.

16. Bax. A.; Davis. D. G. J. Magn. Reson. $1985,65,355$.

17. Macura. S.: Ernst. R. R. Hol. Phws. 1980. 11, 95.

18. Bax. A; Davis. D. G. J. Hagi. Reson. 1985, 63, 207.

19. Bodenhausen. G.: Rubent. D. T. J. Chem. Phys. Lett. 1980. 69. 185 
20. Clore. G. M.: Gronenborn. A. M. CRt C Crit. Rev Biochem. Mol. Biol. 1989. 24. 479 .

21. Clore, G. M: Gronenborn, A. M. Protein Sci. 1994 $3,372$.

22. Brünger A. T. A-PLOR Afanal, lersion 3.I: Yale University: New Haven, CT.

23. Wüthrich. K.: Billeter. M.: Braun. W. J. Mol. Biol. 1983. 169. 949.

24. Clore. G. M:: Gronenborn. A. M.: Nilges. M: Ryan. C. A. Biochenistry 1987. 26.8012.

25. Nilges. M. Clore. G. M. Gronenbon, A. M. FEBS Lett 1988. 229.317 .
26. Kuszewski. T.: Nilges. M.: Brünger. A. T. J. Bionol. M. $R$ R 1992. 2. 33.

27. Wuthrich. K. MAR of Protein and Nucleic Acid. WileyInterscience: New York. 1986.

28. Knoche. L. M. J. Am. Chem. Soc. 1984. J06, 3863

29. Gellman. S. H.: Adams. B. R.: Dado. G. P. J. Am. Chem. Soc. 1990. 112.460 .

30. Lee. H.: Kim. H. K.: Lee. J. H.: You. W. K.: Chung. S. I.: Chang. S. I.: Park, M. H.: Hong, Y. K.: Joe, Y. A. Arch Biochent Biophns. 2000. 375(2), 359 .

31. Davidson, D. J. et al. International patent Wo 97:41824. 